\title{
Vincular financiamento com qualidade: um desafio ainda presente à educação brasileira
}

\author{
To link funding and quality: \\ a challenge still present to brazilian education
}

\section{Vincular financiación en la calidad en educación: un desafío aún presente en Brasil}

\section{BINHO MARQUES* FLÁVIA NOGUEIRA**}

\begin{abstract}
RESUMO: O CAQ interessa a toda a sociedade, mas ainda não se viabilizou como política pública. Postulamos que os caminhos que levaram à mais fácil compreensão do conceito foram os mesmos que contribuíram para a sua inviabilização, dada a inconsistência técnica e a inviabilidade financeira da proposta. Reapresentamos aqui as ideias que desenvolvemos no MEC em 2015, atualizadas. Nossa expectativa é contribuir no debate do novo Fundeb, associando-o ao desafio ainda presente de vincular financiamento com condições efetivas de oferta na Educação Básica pública brasileira.

Palavras-chave: Financiamento. Qualidade da oferta. CAQ como política pública.
\end{abstract}

\begin{abstract}
Cost of Quality Education per Student (CAQ) is of interest to the whole of society, but it has not yet become a public policy. We postulate that the paths that led to the easier understanding of the concept were the same ones that contributed to is preclude, given the
\end{abstract}

\footnotetext{
* Historiador, mestre em Educação (UFRJ), foi professor de escolas públicas, coordenou programas comunitários com Chico Mendes, ocupou os cargos de Secretário de Educação Municipal e Estadual de Educação e Secretário Estadual de Inclusão Social, foi eleito Vice-Governador e Governador do Acre e esteve à frente da SASE/MEC como Secretário Nacional. Atualmente desenvolve trabalhos de consultoria na área de políticas públicas em Educação.

** Bióloga, Doutora em Ecologia (UFSCar), é professora aposentada da UFMT. Coordenou o PPG Ecologia, atuou como Pró-Reitora de Pós-Graduação, Secretária Estadual de Ciência e Tecnologia, Diretora Científica da FAPEMAT e Diretora na extinta SASE/MEC. Atualmente desenvolve trabalhos de consultoria na área de políticas públicas em Educação. E-mail: <fnog1963@gmail.com>.
} 
technical inconsistency and the financial unfeasibility of the proposal. Here, we present the ideas we developed at the Ministry of Education (MEC) in 2015, updated. Our expectation is to contribute to the debate of the new Fund for Basic Education and for Enhancing the Value of the Teaching Profession (Fundeb), associating it with the still present challenge of linking financing with effective conditions of supply in the Brazilian public basic education.

Keywords: Financing. Quality of offer. CAQ as public policy.

RESUMEN: El Costo Alumno-Calidad es de interés para toda la sociedad, pero aún no se ha convertido en una política pública. Postulamos que los caminos que condujeron a una comprensión más fácil del concepto fueron los mismos que contribuyeron a su inviabilidad, dada la inconsistencia técnica y la inviabilidad financiera de la propuesta. Aquí presentamos las ideas que desarrollamos en MEC en 2015, actualizadas. Nuestra expectativa es contribuir al debate del nuevo Fundeb, asociándolo con el desafío aún presente de vincular la financiación con condiciones efectivas de oferta en la Educación Básica pública brasileña.

Palabras clave: Financiación. Calidad de la oferta. CAQ como política pública.

\section{Introdução}

\footnotetext{
igualdade de condições para o acesso e permanência na escola, com aprendi1 zado, é o primeiro princípio constitucional que deve orientar a organização da 1 política educacional. Nesse contexto, a adoção de referenciais nacionais obrigatórios é basilar para a garantia desse direito, pois o Brasil - grande, diverso e desigual - define na Constituição que a educação é nacional. Para garantir a equalização de oportunidades e o padrão mínimo de qualidade a Constituição também estabelece a função redistributiva e supletiva técnica e financeira da União e dos estados. A Lei nº 9.394/1996 (Lei de Diretrizes e Bases da Educação - LDB) completa o cenário, definindo que a União, em colaboração com os estados, o Distrito Federal e os municípios, deve estabelecer um padrão mínimo de oportunidades educacionais, baseado no cálculo do custo mínimo por aluno, capaz de assegurar ensino de qualidade (Artigo 74).
} 
Assim, se a educação é um direito constitucional e o poder público, no contexto federativo, deve se organizar para garanti-lo, o Custo Aluno Qualidade (CAQ) interessa a toda a sociedade. Mas por que não se viabiliza como política pública?

\section{Um pouco da história}

O conceito de CAQ, com diferentes nomenclaturas, já aparecia nos debates acadêmicos do final dos anos 80 (MELLO, 1989), mas foi na Conferência Nacional de Educação Para Todos (BRASIL, 1994) que ele ganhou força teórica e musculatura política. A ideia de um "CAQ" era embalada pelas mais diversas correntes do pensamento acadêmico, governos e movimentos sociais ${ }^{1}$, que pensavam na criação de um mecanismo redistributivo capaz de assegurar condições básicas nacionais de qualidade, vinculadas a um valor que fosse suficiente para o seu financiamento, garantindo, inclusive, o pagamento de um piso nacional para os professores.

O Acordo Nacional assinado em 1994 foi o marco histórico que concretizou esse princípio, ao unir o Ministério da Educação, a Confederação dos Trabalhadores da Educação (CNTE), a União Nacional dos Dirigentes Municipais de Educação (Undime), o Conselho Nacional de Secretários de Educação (Consed) e academia em torno de uma ideia de CAQ.

A força política do Acordo influenciou em grande medida o início do Governo Fernando Henrique Cardoso e levou à criação do Fundef em 1996. O texto legal aprovado, porém, frustrou expectativas, porque a vinculação do financiamento a referenciais nacionais de qualidade para toda a educação básica não estava presente. Os debates em torno da vinculação ganharam depois novo impulso, no período que precedeu a criação do Fundeb (2006-07), quando o Inep disponibilizou estudos na tentativa de construir um mecanismo que se aproximasse do conceito original de CAQ (FARENZENA, 2005; CAMARGO, OLIVEIRA, CRUZ E GOUVEIA, 2006; VERHINE, 2006). Mas o processo foi interrompido quando o MEC optou por um caminho estritamente financeiro, abandonando definitivamente, na lei, a vinculação.

Apesar da descontinuidade da iniciativa governamental, a sociedade civil não permitiu que o movimento de construção do conceito fosse interrompido. Organizações como Ação Educativa, Campanha Nacional pelo Direito à Educação (Campanha) e CNTE assumiram a liderança do processo, deram continuidade aos estudos e promoveram intensa mobilização. Como desdobramento desse esforço foi introduzido o conceito de CAQi (CARREIRA; PINTO, 2007), que deveria suceder o valor mínimo nacional aluno/ano do Fundef. Mas, mais uma vez, o desenho final do novo Fundo, criado agora no Governo Lula, frustrou expectativas. Mesmo ampliado para toda a educação básica, o Fundeb se afastou ainda mais dos ideais de vinculação financiamento/qualidade. 
Nos anos seguintes, pela força da mobilização social, o CAQi ganhou força e acumulou expressivas vitórias políticas. Uma delas foi a aprovação do Parecer CNE/CEB 08/2010, que associou a disponibilidade de uma lista de insumos à possibilidade de se atingir Ideb 6,0 (BRASIL, 2010). Mas ao longo de sua tramitação nos diferentes órgãos do MEC recebeu posicionamentos que revelaram concordâncias, lacunas e discordâncias, caracterizando, por dois anos, um cenário de desacordo interno e profundo silêncio sobre o tema. Apenas em 2012, por nossa insistência (pois estávamos à frente da Secretaria de Articulação com os Sistemas de Ensino, a hoje extinta Sase/MEC), o processo foi devolvido ao CNE para reanálise, na expectativa de uma construção conjunta de caminho possível para a implantação do CAQi.

Outro período de silêncio governamental teve início, sendo quebrado apenas em 2013, durante o Fórum de Avaliação do Financiamento da Educação Básica Nacional, ocorrido em julho (BRASIL, 2013), que coordenamos. Mais uma vez, por nossa insistência, o tema foi trazido para a centralidade do debate do financiamento. No Fórum os Secretários Romeu Caputo (SEB) e Binho Marques (Sase) explicaram publicamente as razões da discordância do MEC com a proposta do CNE, mesmo demonstrando que as divergências internas ainda não haviam sido sanadas.

Em 2014, o CAQi/CAQ foi incorporado à Lei do PNE (Lei nº 13.005/2014). A mobilização social para a adesão dos congressistas se valeu de argumentos financeiros construídos pela Campanha e pela Associação Nacional de Pesquisadores em Financiamento da Educação (Fineduca), que contabilizava como receita apenas os recursos oriundos do Fundeb. O cálculo omitia os cerca de $40 \%$ de receitas dos estados e municípios que complementam o financiamento da educação no Brasil, definindo para a União, como consequência, a necessidade de uma complementação superior a $\mathrm{R} \$ 46$ bilhões por ano, considerando valores de 2012 (FINEDUCA, 2013).

Por força da lei, a responsabilidade pela implantação do CAQi naturalmente pesou sobre o MEC. Dedicando especial atenção ao cumprimento das metas do PNE, o ministro Renato Janine Ribeiro, em 2015, criou um Grupo de Trabalho(GT) de caráter interno "para elaborar estudos sobre a implementação do Custo Aluno-Qualidade-CAQ, como parâmetro para o financiamento da educação básica" (PORTARIA GM 459/2015, BRASIL, 2015a). O GT resgatou aspectos históricos e legais, fez estimativas, apresentou uma visão conceitual e metodológica do CAQi/CAQ e propôs um caminho para sua implantação gradativa. Mais de sessenta pessoas foram ouvidas, entre especialistas, representantes dos movimentos sociais e sindicalistas, em rodadas de escuta cujas atas foram integralmente disponibilizadas nos anexos do Relatório (BRASIL, 2015b).

Esse foi, sem dúvida, o momento mais próximo que o CAQi esteve de sua efetiva implantação. O Relatório foi apresentado ao ministro Aloísio Mercadante, já que ficou pronto no dia em que o ministro Janine deixou o Ministério. O ministro Mercadante, que em sua primeira passagem pelo MEC havia devolvido o Parecer CNE/CEB 08/2010 para 
reexame, resolveu consultar a Campanha sobre as propostas, mas a direção da entidade as refutou por completo.

Por sugestão da própria Campanha, o Ministro formou outro grupo para estudar o assunto, que nunca se reuniu. Vivíamos o período mais conturbado do Governo Dilma, que resultou no golpe parlamentar de 2016. O Relatório foi muito pouco lido e divulgado. Aproveitamos, portanto, mais uma oportunidade para expor nossa principal hipótese e para reapresentar as ideias do GT, agora atualizadas. Nossa expectativa é contribuir com o debate do novo Fundeb, associando-o aos dispositivos do PNE, na sequência do que já fizemos em Marques e Nogueira (2018).

\section{A proposta de 2015}

Postulamos que, paradoxalmente, os caminhos que levaram à fácil compreensão do conceito de CAQi/CAQ ao longo dos anos pela sociedade foram os mesmos que contribuíram para a sua inviabilização como política pública. O CAQi, como é amplamente defendido hoje, tornou-se popular por se estruturar de maneira simplificada em duas ideias força de fácil assimilação pelo senso comum: a primeira é que a garantia de acesso a uma lista de insumos pelas escolas, padronizada nacionalmente, pode assegurar a qualidade desejada - o que foi "traduzido" pela possibilidade de se atingir o Ideb 6,0 no Parecer CNE/CEB 08/2010. A segunda ideia é que se pode transferir integralmente para a União a complementação de um CAQi que subestima a capacidade financeira dos estados e municípios com maior arrecadação, por considerar apenas a fonte Fundeb. A proposta não considera que o Fundo representa, em média, somente $60 \%$ do recurso total destinado à educação no Brasil e que tem distorções que precisam ser corrigidas. Pela proposta, Campanha e Fineduca recomendam que a União multiplique por cinco a sua parcela de complementação para a garantia do valor necessário ao financiamento (CAMPANHA, 2018).

Na proposta do GT/CAQ/MEC em 2015, a qualidade foi tratada como uma matriz de condições objetivas e não objetivas. As primeiras se referem à infraestrutura, profissionais qualificados e valorizados, projeto pedagógico coletivamente construído e assistência suplementar aos alunos, como alimentação e transporte, por exemplo. As não objetivas, por sua vez, dizem respeito a questões como ênfase e expectativa no aprendizado dos estudantes, responsabilidades e direitos definidos, liderança firme e participativa, monitoramento contínuo, envolvimento da comunidade atendida e busca de aperfeiçoamento contínuo das relações democráticas. Afirmamos que a política pública precisa garantir as condições objetivas para que cada creche ou escola possa desenvolver o conjunto das características que ensejarão o aprendizado e a trajetória dos alunos, concretizando seu direito, e isso é muito mais do que uma lista de insumos. Precisa, portanto, considerar a 
necessidade de recursos, a melhoria da gestão e a criação e o fortalecimento das estruturas de controle social.

Por esta razão o Relatório associou o CAQi/CAQ a um conjunto de referenciais nacionais organizados em seis dimensões ${ }^{2}$ e organicamente vinculados a um Sistema Nacional de Avaliação da Qualidade da Oferta da Educação Básica. A perspectiva era o desenvolvimento de mecanismos permanentes de aprimoramento dos indicadores educacionais para muito além daqueles focados no desempenho dos estudantes como fazemos hoje no Brasil, para inclusive entrar em consonância com o Artigo 11 da Lei do PNE.

Isto significa dizer que a qualidade, para ser orientadora do financiamento e da ação supletiva efetivamente equalizadora no federalismo brasileiro, precisa ser traduzida em dimensões e indicadores identificáveis, aferidos e oficialmente acompanhados por um sistema avaliativo democraticamente construído e permanentemente monitorado pela sociedade. Sem um Sistema Nacional de Avaliação com esse caráter, o incremento de recursos terá pouco ou nenhum impacto, pela incapacidade de orientar os sistemas de ensino para práticas que efetivamente incidam na melhoria da qualidade da oferta.

A proposta considerava também que o atual Fundeb é importante, porém insuficiente, para organizar a passagem de valor mínimo aluno/ano para CAQi. Para uma ação redistributiva e supletiva mais justa, seria necessário considerar a totalidade de recursos atualmente vinculados à educação de cada ente federativo, criando o que chamamos de VAA Total, além de corrigir algumas das distorções redistributivas do Fundo. Nesse aspecto, ao conhecer a real capacidade de financiamento de cada um, o Relatório sugeria a complementação da União por ente federativo, e não por Unidade da Federação, porque comprovadamente há uma ineficiência redistributiva dos recursos, cristalizando e até ampliando iniquidades. Os cálculos foram confirmados por Tanno (2017) como sendo da ordem de $30 \%$. Além disso, o Relatório apontava a necessidade urgente de estudos que demonstrassem, na realidade das escolas brasileiras, os custos efetivos da oferta de cada etapa, segmento e modalidade da educação básica no Brasil, considerando que o conhecimento dos custos reais e regionalizados seria indispensável para aperfeiçoar os fatores de ponderação.

Havia ainda a indicação de ampliação do aporte de recursos da União, além da necessária revisão dos programas universais e focalizados, atualmente utilizados no exercício da função supletiva.

Isso não é pouca coisa, pois a ideia era que mais recurso fosse descentralizado para decisões na ponta. Esse caminho, rejeitado pela Campanha, recomendava ao ministro um cronograma de aumento da complementação da União ao Fundeb na ordem de 1\% ao ano, começando em 2017. O objetivo era alcançar 17\% de complementação da União em 2020 e a criação imediata de uma ação suplementar especial do FNDE, através de extinção de programas nacionais pouco eficazes e uma ação mais focalizada via PAR (Lei n⿳o 
12.695/2012). Esses mecanismos viabilizariam o CAQi de maneira provisória e seriam permanentemente incorporados ao novo Fundeb a partir de 2020.

Outro ponto importante da proposta era que a ampliação dos recursos para os entes federativos deveria acontecer de forma concomitante ao aperfeiçoamento de mecanismos de melhoria da gestão. Por isso, a implantação do CAQi/CAQ dependeria do fortalecimento das ações de assistência técnica. Mais uma vez, sem um consistente Sistema de Avaliação da Qualidade da Oferta, porém, a proposta não se sustentaria, pois é necessário saber quais entes federativos são efetivamente mais frágeis para que também o aporte de recursos técnicos seja maior.

O texto enfatizava ainda que o efeito equalizador decorrente da maior participação da União não poderia reduzir a eficiência fiscal federativa, "acomodando" estados e munícipios com baixo esforço de arrecadação e desestimulando aqueles que já realizavam efetivo esforço e destinação de recursos para a educação básica. Isso exigiria um esforço de aperfeiçoamento de instrumentos que dão visibilidade pública aos mecanismos de arrecadação de cada ente federativo.

\section{O fim de um ciclo}

Entre 2016 e 2018 o assunto foi abandonado pelo MEC; no início de 2019 o Conselho Nacional de Educação se posicionou quanto ao Parecer CNE/CEB nº 8/2010, que estava aguardando reexame desde 2012, aprovando o Parecer CNE/CEB 03/2019 (Brasil, 2019), homologado pelo ministro em 29 de abril de 2019.

A relatora, Maria Helena Guimarães Castro (Presidente da Undime na assinatura do Acordo Nacional e uma das primeiras pessoas a se manifestar pela necessidade de se definir o Custo Aluno Qualidade na Conferência Nacional da Educação para Todos), se posicionou "contrariamente à competência que foi exercida pela Câmara de Educação Básica no sentido de definir o valor financeiro do CAQi no âmbito do Parecer CNE/CEB n-o 8/2010".

Maria Helena tinha em mãos um estudo técnico de 2017 contratado pela Unesco (Almeida Jr., 2018), que resgatava os principais aprendizados construídos pelo GT do MEC e sugeria caminhos para o CNE contribuir, dentro de suas atribuições, para a implementação do CAQi.

Dizia o estudo:

A iniciativa de enfrentamento do tema pela Câmara de Educação Básica reveste-se de elevado significado, pois aponta para a retomada institucional da defesa do CAQi como instrumento prioritário para a garantia do direito de cada estudante no Brasil. Ao mesmo tempo enriquece o debate sobre a necessidade de aperfeiçoamento do atual modelo nacional de financiamento, em especial do atual FUNDEB, com prazo de vigência até 2020 . 
Indo além, o documento reforçava o papel do CNE para a implementação do CAQi:

\begin{abstract}
O texto aqui apresentado tem por objetivo subsidiar este trabalho, reconstruindo a linha do tempo desde os primeiros referenciais teóricos e políticos que deram origem ao conceito de CAQi até os acontecimentos que marcam o impasse dos dias atuais, aprofundando o debate sobre os aspectos conceituais e legais que dão sustentação ao conceito e tratando das principais divergências sobre os mecanismos para sua implantação comparando as principais propostas em debate. Por fim, apresenta um possível mecanismo operacional para o CAQi e oferece uma proposta de agenda para a sua implantação.
\end{abstract}

A relatora optou por incorporar a seu Relatório apenas a parte do estudo que dizia respeito ao debate teórico e conceitual e às deficiências do financiamento da educação nacional. Para a relatora, compete ao $\mathrm{CNE}$

\begin{abstract}
mediar o processo, contribuindo para o debate qualificado da vinculação de referenciais nacionais de qualidade da oferta e o financiamento da educação no país, a partir do diálogo institucional entre o MEC, os sistemas de ensino subnacionais responsáveis pela oferta de educação básica (em especial os Conselhos de Educação) e as representações sociais dos fóruns de educação.
\end{abstract}

Nada mais se fez a partir da homologação desse Parecer e vivemos, assim, o fim de um ciclo. Entre 1993 e 2016 os governos que se sucederam, mesmo com diferentes matizes ideológicas e programáticas, deram relevo à educação, mas essa realidade deixou de existir com a saída da presidente Dilma Rousseff. A Emenda Constitucional 95/2017 é um marco simbólico que sinaliza o fim de um ciclo virtuoso de mais de 20 anos na educação do Brasil, com universalização do ensino fundamental, expansão de matrículas na educação infantil e ensino médio, Acordo Nacional, Fundef e Fundeb, Saeb, Enem e Ideb, Parâmetros Curriculares Nacionais e Base Nacional Comum Curricular, a criação da Sase e da Secadi e, entre outras iniciativas importantes, pela aprovação de três Planos Nacionais de Educação. Infelizmente não pudemos colocar nessa lista a implantação do CAQi, apesar dos esforços feitos em 2015.

\title{
Um mecanismo ainda possível
}

As condições políticas atuais são impeditivas para qualquer proposta progressista no campo da educação. Entendemos por proposta progressista aquela de caráter republicano, que aponta para a construção de um Sistema Nacional de Educação, associando a autonomia dos sistemas subnacionais com práticas democráticas de pactuação federativa e ações nacionalmente articuladas em torno de propósitos comuns, baseadas em referenciais de qualidade para um ensino público, gratuito e laico para todos e todas. Mas abre-se uma fresta. 
A agenda de renovação do Fundeb no Congresso Nacional pode ser uma nova oportunidade para finalmente vincular financiamento com qualidade. Essa é a tarefa das forças progressistas no momento. Com base nos preceitos legais e debates acumulados ao longo de tantos anos e por tantas pessoas, é possível implantar o CAQi na configuração do novo Fundeb, desde que sejam resgatados os princípios conceituais básicos debatidos na origem do conceito.

Em um país de dimensões continentais, com desigualdades sociais e com diversidades que devem ser valorizadas, o melhor caminho não parece ser tentar garantir a todas as escolas a mesma lista de insumos. Uma política pública não pode desconsiderar a diversidade brasileira, nem a capacidade das redes e sistemas de ensino definirem livremente os insumos que julgam importantes para garantir qualidade da oferta diante de realidades substancialmente diferentes. Mas para serem tratadas com apoio técnico e financeiro de forma republicana, as condições de cada uma precisam ser aferidas por um consistente e ampliado Sistema Nacional de Avaliação.

Com transparência de resultados na avaliação das condições de oferta e conhecendo o real valor por aluno disponível, a sociedade poderá cobrar e responsabilizar os gestores. A construção do novo Fundo, ancorada no conceito de CAQ, deverá ampliar a qualidade e a eficiência do controle social e dos competentes órgãos de fiscalização, tornando mais visível a capacidade de investimento de cada ente federativo e melhorando a tradução dos investimentos em entregas objetivas de serviços educacionais, com melhores condições de trabalho nas redes de ensino e com qualidade de aprendizagem, direito constitucional de todas e todos no Brasil.

Recebido em: 21/09/2019 e Aprovado em: 29/09/2019

\section{Notas}

1 Durante o Painel I da Conferência Nacional de Educação Para Todos (Integração União-estados-municípos: financiamento e regime de cooperação) (Brasil, 1994:457-487), a secretária de educação fundamental do MEC, Maria Aglaê de Medeiros, defendeu como uma das prioridades para o Ministério a "definição de um custo padrão mínimo, examinando em particular a valorização do magistério". A então presidente da Undime, Maria Helena de Castro, na mesma linha, defendeu a definição do que seria um custo aluno qualidade.

2 Acesso; jornada escolar; profissionais; instalações e recursos educacionais; democracia; rede de relações.

3 A proposta do GT/CAQ/MEC (Brasil, 2015) era de 17\% até 2020. 


\section{Referências}

ALMEIDA JR., A. Documento Técnico: CAQi: Custo Aluno Qualidade Inicial para contratação de consultoria na Modalidade Produto. CNE/UNESCO, TOR 04/2017. Disponível em: http://portal.mec.gov.br/index.php?option=com_docman\&view=download\&alias=99801produto-propostas-do-custo-aluno-qualidade-inicial-caqi\&category_slug=outubro-2018-pdf1\&Itemid=30192. Acesso em: 28 jul. 2019.

BRASIL. Conferência Nacional de Educação para Todos. Brasília, MEC/SEF, 1254p. Anais.

Ministério da Educação. Conselho Nacional de Educação (CNE). Parecer CNE/ CEB no 8, de 5/5/2010. Disponível em: http://portal.mec.gov.br/index.php?option=com _ docman\&view=download\&alias $=5368$-pceb008-10\&category_slug=maio-2010pdf\&Itemid=30192. Acesso em: 28 jul. 2019.

Fórum de Avaliação do Financiamento da Educação Básica Nacional. Brasília, SASE/MEC, 2013. Org. Wille, R.M.R \& Nogueira, F. Anais. 337p. Disponível em: http://pne. mec.gov.br/images/pdf/publicacoes/Relatorio_Forum_Avaliacao_Financiamento_Educacao_ Basica_Nacional_julho_2013.pdf . Acesso em: 28 jul. 2019.

Portaria GM 459/2015. Constitui Grupo de Trabalho para elaborar estudos sobre a implementação do Custo Aluno-Qualidade - CAQ, como parâmetro para o financiamento da educação básica. DOU, n. 89, pág 12. Disponível em: http://pne.mec.gov.br/images/pdf/Noticias/ portaria_459_2015_CAQ.pdf. Acesso em: 28 jul. 2019.

GT CAQ (Portaria 459, de 12 de maio de 2015): Relatório Final. Brasília, SASE/ MEC, outubro de 2015. 103p e anexos. Disponível em: http://pne.mec.gov.br/images/pdf/ publicacoes/RELATORIO_FINAL_GT_CAQ_out_15.pdf . Acesso em: 28 jul. 2019.

Ministério da Educação. Conselho Nacional de Educação (CNE). Parecer CNE/CEB no 3, de 26/3/2019. Disponível em: http://portal.mec.gov.br/index.php?option=com_docman \&view=download\&alias=110291-pceb003-19-1\&category_slug=abril-2019-pdf\&Itemid=30192 . Acesso em: 28 jul. 2019.

CARREIRA, D.; PINTO, J. M. R. Custo Aluno-Qualidade Inicial: rumo à educação pública de qualidade no Brasil, Editora Cortez, 2007. 42p. Disponível em: http://www.educadores. diaadia.pr.gov.br/arquivos/File/pdf/qualidade_aluno.pdf . Acesso em: 28 jul. 2019.

\section{CAMPANHA NACIONAL PELO DIREITO À EDUCAÇÃO. O CAQi e o CAQ no PNE:}

quanto custa a educação pública de qualidade no Brasil? São Paulo, 2018. 204p. Formato Ebook disponível em: http://www.custoalunoqualidade.org.br/pdf/quanto-custa-a-educacao-publicade-qualidade-no-brasil.pdf. Acesso em: 28 jul. 2019.

CAMARGO, R.B; OLIVEIRA, J.F.; CRUZ, R.E \& GOUVEIA, A.B. Pesquisa Nacional Qualidade na Educação: problematização da qualidade em pesquisa de custo- aluno-ano em escolas de Educação Básica. Brasília, INEP, 2006. 140p. Disponível em:file://C:/Users/user/Downloads/\%7B9391749B-E2AB4A90-B356-80A43408F537\%7DMIOLO_PesquisaNacional_Qualidade_Volume\%2002.pdf . Acesso em: 28 jul. 2019.

FARENZENA, N. (org.). Custos e condições de qualidade da educação em escolas públicas: aportes de estudos regionais. Brasília, INEP/MEC, 220p. 2005.

FINEDUCA. Por que a União deve complementar o CAQi no PNE? Nota Técnica 01/2013 Disponível em: http://www.redefinanciamento.ufpr.br/nota1_13.pdf Acesso em: 28 jul. 2019. 
GOMES, C.A.; CARNIELLI, B.L.; FERREIRA DE JESUS, W.; LEAL, H.B. O financiamento da educação brasileira: uma revisão da literatura. RBPAE, Uneb: Salvador, v.23, n.1, p. 29-52, jan./abr. 2007, Disponível em: https://seer.ufrgs.br/rbpae/article/viewFile/19012/11043. Acesso em: 28 jul. 2019.

MARQUES, B. e NOGUEIRA, F. Educação no Brasil: o Fundeb+ como oportunidade. IN: Educação em debate. São Paulo: Moderna, 2018. p. 55-63. Disponível em: http://www.crianca.mppr.mp.br/arquivos/ File/publi/santillana/educacao_em_debate.pdf. Acesso em: 28 jul. 2019.

MELLO, E. Implicações do financiamento da educação na gestão democrática do ensino público de primeiro grau. Em Aberto, 42, Brasília: INEP/MEC, abr.jjun. de 1989.

TANNO, C.R. Universalização, qualidade e equidade na alocação de recursos do Fundo de Manutenção e Desenvolvimento da Educação Básica e de Valorização dos Profissionais da Educação (FUNDEB): proposta de aprimoramento para a implantação do Custo Aluno Qualidade (CAQ). Estudo Técnico nº 24/2017-CONOF/CD. Câmara dos Deputados. Brasília, 2017. 123p Disponível em: https:// www2.camara.leg.br/atividade-legislativa/comissoes/comissoes-temporarias/especiais/55a-legislatura/ pec-015-15-torna-permanente-o-fundeb-educacao/documentos/outros-documentos/estudo-daconsultoria-de-orcamento-da-camara-dos-deputados. Acesso em: 28 jul. 2019.

VERHINE, R. E. Custo AlunoQualidade em Escolas de Educação Básica - 2ª Etapa. Relatório Nacional da Pesquisa. Universidade Federal da Bahia, Brasília, Inep, 2006. Disponível em: <http://www. publicacoes.inep.gov.br/portal/download/464>. Acesso em: 28 jul. 2019. 